\title{
Optimal Exchange Rates: A Market Microstructure
}

\section{Approach}

\author{
Alexander Guembel \\ Lincoln College \\ and \\ Saïd Business School \\ University of Oxford
}

Oren Sussman*

Wadham College

and

Saïd Business School

University of Oxford

July 13, 2004

\begin{abstract}
Motivated by the observation that exchange-rate management resembles market making, we use microstructure theory in order to conduct a welfare analysis of exchange-rate management, including the "corner solutions" of a free float and a fixed peg. We show that a policy that smoothes out exchange-rate fluctuations needs to
\end{abstract}

\footnotetext{
*Acknowledgments: We would like to thank conference participants at the CRENOS 2001 meetings and seminar participants at Duke University, the Federal Reserve Bank of Philadelphia, and LSE (FMG workshop). We would also like to thank Tim Bollerslev, Pete Kyle, Richard Lyons, Colin Mayer, S. Viswanathan, Paolo Vitale, and Joseph Zeira for helpful comments. Guembel would like to thank the Fuqua School of Business, where part of this research was carried out, for their kind hospitality. Sussman would like to thank the Monaster Center at Ben-Gurion University for supporting this research. Correspondence to either author at Saïd Business School, Park End Street, Oxford, OX1 1HP.
}

E-mail addresses: Guembel: alexander.guembel@sbs.ox.ac.uk; Sussman: oren.sussman@sbs.ox.ac.uk 
trade off the welfare gain due to lower risk exposure of local producers against the trading losses that the policy would generate owing to speculation. We identify the conditions under which exchangerate management can increase welfare and argue that these conditions are more likely to be satisfied in illiquid markets, mainly small economies and emerging markets. We also explore the role of a Tobin tax (assuming enforceability) in facilitating exchange-rate management. (JEL: E58, F31, G14, O24) 


\section{Introduction}

The argument that private exchange speculation will not provide sufficient smoothing of exchange fluctuations is sometimes used to justify ... extensive intervention by individual governments ... to even out minor fluctuations in exchange rates. ... [However], if they [governments] lose money, they make gifts to other speculators or traders, and the primary cost ... is born by them. Friedman 1953, pp. 187-188.

There is a remarkable similarity between market makers in dealership markets like the New York Stock Exchange (NYSE) - and those central banks, particularly in small and illiquid markets, who manage their foreign exchange (FX) markets. ${ }^{1}$ This similarity is apparent in two main respects. First, in both cases the declared objective of the respective agencies is to deepen the market and smooth price fluctuations. For example, the Constitution and Rules of the NYSE state that a specialist should provide for a "fair and orderly market ... [which] implies the maintenance of price continuity with reasonable depth and the minimizing of the effect of temporary disparity between supply and demand." ${ }^{2}$ To the same effect, when Israel 'floated' its exchange rate in 1977, the central bank reported that "the involvement of the central bank is [now] limited to moderating the effect of short-term random fluctuations in the demand and the supply for foreign currency on the exchange rate. Non random changes in the supply and the demand will affect mainly the exchange rate and not the economy's foreign reserves." 3 Presently, the bank abstains from day-to-day intervention; however "should the need arise, the foreign currency department can intervene through the purchase or sale of foreign currency." 4

\footnotetext{
${ }^{1}$ For more detail on dealership markets see Pagano and Roell (1990), Ellul (2001), and Viswanathan and Wang (2002).

${ }^{2}$ See Rule 104 regarding the functions of the specialist.

${ }^{3}$ See the Bank of Israel's 1977 Annual Report p. 231 (Hebrew). Hence, "fear of floating" is not a new phenomenon; see Calvo and Reinhart (2002), although in their view a fear of floating is ultimately fear of inflation.

${ }^{4}$ Bank of Israel website.
} 
Second, while implementing their price-smoothing strategies, the respective agencies typically lose money to sophisticated speculators. As for the NYSE, Panayides (2004) documents the restrictions imposed by the exchange on specialists' trading so as to preserve price continuity. He estimates that losses while trading under the imposed constraint amount to $\$ 3,824$ per stock per day (averaged across 35 "highly active" stocks), against a daily profit of $\$ 6,160$ while trading unconstrained. Systematic studies of central banks' trading losses are scarce. Taylor (1982) documents some of the tricks employed by central banks to hide the losses off the accounts. His own rough estimates show a strong tendency toward heavy losses among central banks of nine developed economies who had (at the time) "floating" exchange rates, up to $\$ 3.7$ billion lost by the Central Bank of Italy over the period $1973-1979 . .^{5}$ Increasingly, trading losses are perceived as a binding constraint on exchange-rate management. While reporting an estimated trading loss of $£ 3$ billion by the Bank of England during a single day, The Economist commented that perhaps the underlying exchange-rate policy was "the right thing to do, but at a time when public expenditure restraint is supposed to be at the top of the government's agenda, it is worth asking what was the cost to the taxpayer." ${ }^{6}$ To the same effect, one of the main reasons why the Bank of Israel stopped its daily intervention was that "continued and prolonged intervention through selling reserves may increase uncertainty and strengthen the tendency towards capital exporting and a speculative attack ... which will levy a high cost on the State's treasury." 7

The similarity described here puts into a different perspective some of the classical arguments about exchange-rate policy. If providing liquidity - even at a loss - is an essential role of profit-oriented market entities, then the price-smoothing role of the state should not be dismissed as easily as in Friedman (1953); since liquidity is a public good, a state that has access to taxation (and hence need not break even), must have an advantage over private institutions in providing it. This leads us to the idea that exchange-rate

\footnotetext{
${ }^{5}$ Inflate by a factor of 2.5 in order to adjust for current prices.

6 "Black Wednesday", 16 September, 1992, the day Britain was forced to abandon the ERM; see The Economist, 10 October, 1992.

${ }^{7}$ Bank of Israel 1998 Annual Report, p. 196.
} 
policy can be perceived and analyzed as an attempt by the state to "make the FX market" on social welfare rather than on profit grounds. An immediate implication of such an approach is that the structure of the market is crucially important in determining the role of the state. Presumably, the scope for policy is quite different for developed markets with sophisticated financial instruments and an active provision of liquidity relative to small, illiquid and emerging markets.

In order to develop this idea, we model the dealership FX market of a small open economy with terms-of-trade uncertainty and fairly rudimentary financial markets. Lyons (1997) suggests a formalization that captures some of the specific features of FX dealership markets. Nevertheless, we use the more tractable formalization of Kyle (1985) (see further discussion of this point at the end of this section). With no state intervention, the economy is already served by some FX dealers who provide liquidity out of profit-oriented motives, a setting that we interpret as a free-float exchange-rate regime. ${ }^{8}$ The basic question that we address is whether the state can improve social welfare by "taking over" the FX market and then imposing on the dealers a trading policy that differs from the free float, compensating them for ex ante trading losses by lump-sum transfers. We are obviously aware of the fact that most real-world FX management is done via open-market operations rather than by interfering with dealers' trading. ${ }^{9}$ We chose this formalization in order as to preserve a well-defined measure of social welfare. We treat the central bank as a welfare-oriented intermediary that can change the allocation of risk among "real" agents, but does not have any risk-bearing capacity of its own. If (alternatively), the state traded against its own portfolio, then the risky return

\footnotetext{
${ }^{8} \mathrm{~A}$ survey by the Bank of International Settlements (BIS) shows that in the USD-Euro market, $56 \%$ of the turnover is executed aganst dealers and $32 \%$ against financial institutions. The figures for the USD-JPY market are 57\% and 29\%; for the USD-residual currencies markets, the figures are $56 \%$ and 30\%, respectively. See Table E-2 in the BIS's Triennial Survey of Foreign Exchange Markets, April 2001.

${ }^{9} \mathrm{It}$ is interesting to note, however, that for many years the Bank of Israel had a monopoly over FX dealership. Essentially, the FX market consisted of a daily batch auction conducted by the bank itself; see Djivre (1993) and Djivre and Tsiddon (2001). Obviously, this arrangement provided an easy (and confidential!) vehicle for exchange-rate intervention.
} 
on that portfolio would have to be borne by some taxpayers. Essentially, the current formalization allocates these returns to the dealers.

We report five main results. First, a free-float exchange-rate regime is generically inefficient. This follows from the basic tension that exists in the model between the risk-sharing role of prices and their informational efficiency. In our model, markets are incomplete and local producers hedge against terms-of-trade shocks by taking FX positions. However, the FX market is opened only after some fundamental information has already leaked out to some of the better-informed (foreign) speculators; if the market is informationally efficient, some of this information will be incorporated into equilibrium prices. By the well-known Hirshleifer (1971) effect, this early revelation of information destroys some insurance opportunities.

Second, the extreme case of a fixed peg is not feasible, let alone optimal. The reason is that, since the free float is informationally efficient, any deviation would create a profit opportunity that will be utilized by speculators. In the limit, when the exchange rate is perfectly smoothed, speculators would inflict infinite losses on the local dealers. Taking the first two points together, it is clear that both "corner solutions" of the free float and the fixed peg have no particularly attractive welfare properties. ${ }^{10}$ It is noteworthy, however, that in our setting there is a sharp distinction between dollarization (dollarbacked local currency) and a fixed peg (local-assets-backed local currency with a price still pegged to the dollar). The infeasibility result applies to the fixed peg but not to dollarization.

Third, although the free float is generically inefficient, it is not clear in what direction policy should operate. This is because policy is driven by two conflicting motives, in parallel to the dual role of prices. On the one hand, smoothing the exchange rate improves the risk-sharing role of prices. On the other hand, deviations from informational efficiency generate trading losses that ultimately fall on the taxpayer. It is not clear a priori which effect dominates ; in theory, it might be optimal to reverse the policy and trade the currency for rent-seeking motives, bearing the social cost of increased consumption

\footnotetext{
${ }^{10}$ See Fischer (2001) and Frankel, Schmukler, and Serven (2001).
} 
volatility. A crucial insight offered by the analysis is the inherent conflict between the two motives. Central banks are constantly searching for a policy that would both deter speculation and smooth exchange rates. We suggest that probably the two objectives cannot be satisfied simultaneously.

Fourth, we show that — under some fairly plausible conditions — combining exchangerate management with a small (positive) speculation-deterring Tobin tax can enhance welfare ( $i f$, indeed, the tax can be enforced). This is in spite of the fact that the tax is levied on speculators and other traders alike and thus distorts some "legitimate" hedging. Moreover, with a Tobin tax the policy of a fixed exchange rate would be feasible (no optimality of such a mix is implied). In our analysis, the tax is desirable not just for its own sake but mainly as a facilitator of exchange-rate management, slowing down the speculative forces that might disable it. ${ }^{11}$

Lastly, in spite of our third result, we derive a remarkably simple rule of thumb to guide policy: the central bank should intervene to smooth the exchange rate in economies where both the free-float elasticity of the exchange rate with respect to the order flow as well as the coefficient of relative risk aversion of local producers are "high". We analyze the determinants of the relevant elasticity and conclude that the condition for smoothing is more likely to be satisfied in emerging markets and small economies. Note, however, that our setting is already oriented toward emerging markets. We can thus strengthen the argument that FX management is suitable mainly for emerging markets. Indeed, our whole analysis rests on the assumption of incomplete markets. In emerging markets, where insurance markets are malfunctioning, the government may try to substitute for them by smoothing the exchange rate; see McKinnon and Schnabl (2003). ${ }^{12}$ Also, the Tobin tax may be interpreted as reflecting high transaction costs on FX transactions, which would facilitate the operation of FX management. Thus, emerging markets tend

\footnotetext{
${ }^{11}$ The tax is originally proposed in Tobin (1978). For microstructure treatments see Subrahmanyam (1998) and Dow and Rahi (2000).

${ }^{12}$ In their own words: "to offset the nonexistent market in forward exchange, the government is induced to provide an informal hedge by keeping the exchange rate stable."
} 
to manage their exchange rates because they already have enough "sand in the wheels".

One more introductory comment is in order. In line with Kyle (1985), we model speculation as trade based upon a private signal of a fundamental macro variable — in our case, the terms of trade. Some would argue that macroeconomic events are by their very nature public and equally well known to all traders in the market. In contrast, Lyons (2001, pp ./ 26-28) argues that private information plays a crucial role in FX markets, but he makes a distinction between two types of private information: fundamental and 'nonpayoff', which is more related to the propensity to trade FX. The distinction is important because the second type of private information is likely to be more dispersed. However, it would be aggregated into the order flow. It is crucial that FX dealers are sooner and better informed about the order flow and thus become the most significant informed traders in FX markets. According to this view, the second type of private information is more common in the liquid markets of the more developed economies. In contrast the first type of private information is likely to exist in emerging markets, particularly if they have an oligopolistic dealership structure and have cozy relations with local politicians (see also McKinnon and Schnabl 2003, Section 3.3). Lyons (1997) offers a formalization of dealership markets with the first type of private information. ${ }^{13}$ In this paper we retain Kyle's (1985) formalization for two reasons. First, it is more tractable for the kind of exercise that we do. Second, because exchange-rate management is more relevant to emerging markets, one might just as well conduct the analysis in a setting that captures their specific features. However, we do not think that this choice of framework limits the results in any way. Based on some experimentation with the alternative setting, we believe that the trade-off between risk sharing and trading is generic and would favor intervention mainly in emerging markets. ${ }^{14}$

\footnotetext{
${ }^{13}$ Another contribution of Lyons (1997) is the analysis of dealers' risk aversion.

${ }^{14}$ For some evidence on private information in FX markets see Ito Lyons, and Melvinet. al . (1998), Evans and Lyons (2002), Cheung and Wong (2000), and Naranjo and Nimalendran (2000). For a more comprehensive discussion and evaluation of these results, see Lyons (2001) and Frankel, Galli and Giovanini (1996).
} 
After a brief discussion of related literature, the remainder of the paper proceeds as follows. The basic model is presented in Section 2, followed by a discussion of the flexible exchange-rate regime in Section 3. Section 4 derives the central results about the optimality of exchange-rate management. A Tobin tax is introduced in Section 5. Section 6 provides a discussion of some positive implications of our theory and concludes with some remarks on robustness. The Appendix contains the proofs.

\subsection{Relation to the Literature}

Traditionally, exchange-rate policy was analyzed within the IS-LM model and relied heavily on price stickiness (see Marston 1985). Obviously, any policy analysis within an ad hoc framework that has no proper welfare measure would be lacking. Recently, important progress has been made in modeling price stickiness within an "optimization framework"; see Devereux and Engel (1998). We do not attempt to survey or evaluate the sticky-prices approach. We would like to emphasize, however, that in our analysis prices are free to adjust instantaneously to market conditions and that policy is evaluated by a standard welfare economics criterion.

Helpman and Razin (1982) were among the first to introduce market incompleteness into exchange-rate analysis. Their results, however, are somewhat inconclusive in determining which regime welfare-dominates the other. Neumeyer (1998) argues that the incomplete-markets argument tends to favor flexible exchange rates over strictly fixed exchange rates, because fixing the exchange rate is like shutting down a market, which in turn would span fewer insurance opportunities. However, this argument applies only to the corner solution of a strictly fixed peg. The analysis is thus more relevant to understanding the welfare properties of currency unions and dollarization programs; it may prove difficult to apply across the set of exchange-rate policies that are employed in most other cases.

There is little research using a market microstructure approach to analyze exchangerate policy. Vitale $(1999,2003)$ models central bank intervention in FX markets in 
a microstructure setting, focusing on the interaction between the FX market and the classic macroeconomic problem of credible commitment in a setting with an expectationsaugmented Phillips curve. Vitale shows how the central bank may credibly reveal its privately known inflation target through FX operations, which have a stabilizing effect on the economy.

Jeanne and Rose (2002) develop a microstructure model of FX markets aimed at finding a rationale for stabilizing the exchange rate. In their model, based on DeLong et al. (1990), a stabilizing policy drives out destabilizing noise trade. We are somewhat more skeptical about the welfare gains from a stabilizing policy. Stabilizing in our model creates opportunities for speculation, which undermines the policy itself. The difference goes back to the underlying microstructure model: DeLong et al. in their case; Kyle (1985) in ours.

Killeen, Lyons, and Moore (2001) explore the relationship between traders' behavior and the exchange-rate regime during the period between the announcement and implementation of fixed exchange rates in the EMU. They show theoretically and empirically that FX trading strategies are conditioned upon the exchange-rate regime. The sensitivity of exchange-rate movements to order flow therefore disappears upon the introduction of a credible fixed exchange-rate regime. The results of Killeen and colleagues are consistent with one of the main building blocks of our model: that market participants endogenize the exchange-rate regime. We take this insight a step further by developing a normative theory of exchange rate determination.

\section{The Model}

We have in mind a small open economy featuring high exposure to terms-of-trade uncertainty, fairly rudimentary financial markets, and quite active foreign speculators. We start with a description of the fundamental risk, to be followed by a description of the economy's financial structure and insurance opportunities, turning finally to the marketmaking operations of the central bank. 
There are three periods, $t=0,1,2$. We aggregate local production to a single export good, which we shall dub copper. Because of the small size of the economy, the terms of trade are determined exogenously and randomly by world markets. The market for copper opens at $t=2$, where copper is traded against the world's currency, which we shall dub the dollar at a spot price of $P(\$ /$ pound of copper), and

$$
P=\mu_{P}+p, \quad p \sim N\left(0, \sigma_{p}^{2}\right)
$$

Here $\mu_{P}$ is the unconditional mean of the world's price and $p$ is a normally distributed deviation from that mean. Consumption goods are imported from abroad. We normalize the price of the consumption good to unity and use it as a numeraire. We thus use the terms "consumption good" and "dollars" interchangeably.

There is a measure-1continuum of the local copper producers with constant absolute risk aversion (CARA) preferences,

$$
u_{h}(c)=-e^{-\rho_{h} c}
$$

Output is deterministic at $Y$ units of copper and is realized at $t=2$. Hence, GNP denominated in terms of consumption goods is uncertain. Obviously, the local producers would like to share this risk with some other agents. In addition to the local producers, the only other locals are risk-neutral FX dealers. Hence, if financial markets were perfect then dealers would fully insure the local producers. Since markets are incomplete, we turn next to a description of the economy's financial and monetary structure.

A public agency called the central bank has two roles. The first is to issue local currency; this will be the bank's only role in a free-float exchange-rate regime. In a managed exchange-rate regime, the bank may be called upon to intervene in the FX market. As for its first role, we assume that at $t=0$ the bank issues banknotes, which we shall dub pesos, against a portfolio of local assets. For simplicity, suppose that these assets are riskless bonds issued by the local producers and thus denominated in terms of copper. Hence, the bank's balance sheet is simply

$$
M_{0}=\text { copper-denominated bonds, }
$$


where $M_{0}$ is the money base. At the end of the second period, the bank unwinds its position and pays one unit of copper for every peso. The FX market opens at $t=1$; we denote the inverse of the exchange rate by $Q(\$ /$ peso), so that a high $Q$ means a strong peso. It is worth making a few comments about our modeling of money.

(i) Local currency is, essentially, a future contract on copper. As a result, money is priced just like any other short-maturity futures contract. This commodity money approach abstracts from traditional issues concerning the pricing of fiat money in an infinite-horizon economy. Nevertheless, the approach captures one aspect that is both realistic and crucial to our analysis: that the peso will be strong when the world price of copper is expected to be high. In a recent paper, Chen (2002) analyzes exchange-rate determination in commodities-specialized economies using a commodity money approach, providing strong evidence of that effect.

(ii) The quantity theory of money holds: If more peso notes are issued against an existing amount of local bonds, the value of the peso will fall proportionately. However, we assume that the central bank is independent and can commit not to inflate. Note also that open market operations - namely issuing more pesos against more copper bonds - are neutral by Ricardian equivalence, as agents substitute pesos for bonds in their portfolios.

(iii) The central bank may dollarize by issuing pesos against dollars rather than copper bonds. That would peg the value of the peso against the dollar, but it would have no effect on the dollar prices of local assets (copper bonds) on the dollar-denominated income of the local copper producers. In other words, the policy cannot improve risk sharing between copper producers and other agents in the model.

Our crucial assumption is that there is no ex ante $(t=0)$ trade. Moreover, the FX market opens at $t=1$, after some information has been revealed about the $t=2$ spot price of copper. By the well-known Hirshleifer (1971) effect, an early revelation of information destroys insurance opportunities. At this point, it might be useful to develop a first-best benchmark: how the risk-averse copper producers would hedge themselves if they could trade with the dealers at $t=0$. 
Let $c_{h}$ be the $t=2$ local producers' level of consumption. Then

$$
c_{h}=Y P+\pi_{h}, \quad \pi_{h} \equiv m_{h}(P-Q),
$$

where $m_{h}$ is the producers' peso position and $\pi_{h}$ her trading profits. Since pesos are futures on copper, if trade takes place ex ante then the peso should be priced by the riskneutral dealers according to its unconditional mean, $\mu_{P}$. At that price, the risk-averse copper producers take a zero position on copper by shorting the peso at $m_{h}=-Y$, which will set consumption at $Y \cdot \mu_{P}$, deterministically. In simple words, the local producers would borrow $Y$ pesos, use the proceeds to buy dollars, and pay their debt at $t=2$ out of their copper income. Obviously, this hedging strategy breaks down if the FX market opens only at $t=1$, after some of the uncertainty about $P$ has already been resolved. Consider the extreme case where $P$ is fully revealed at $t=1$. Then $P=Q$ and consumption is $Y \cdot P$, with the local producers bearing all the terms-of-trade uncertainty. At this point, any attempt by the central bank to interfere with market prices would result in infinite trading losses. We thus make some further assumptions that imply that, although some sophisticated speculators have superior knowledge about the copper market, that knowledge is only partially revealed at $t=1$.

We assume that there are $N$ risk-neutral foreign speculators. Their (aggregate) demand for pesos is denoted by $m_{s}$, so that their trading profits are

$$
\pi_{s}=m_{s}(P-Q)
$$

At $t=1$, each speculator receives a noisy signal $s$ about the $t=2$ spot price of copper, such that

$$
s=p+\varepsilon, \quad \varepsilon \sim N\left(0, \sigma_{\varepsilon}^{2}\right)
$$

(Note that the signal $s$ is already defined as a deviation from the mean spot price.) Here $\varepsilon$ is uncorrelated with any of the other random variables in the model. By standard results,

$$
E(p \mid s)=\theta s, \quad \theta=\frac{\sigma_{p}^{2}}{\sigma_{p}^{2}+\sigma_{\varepsilon}^{2}}
$$


where $\theta$ is the "precision" of the signal. ${ }^{15}$ In line with the foregoing discussion and with Lyons (1997), one might assume that the speculators have gained their superior knowledge by accessing order-flow information in some foreign copper markets.

However, not all the foreigners are well informed. Suppose that there is a measure-1 continuum of "noise" traders with CARA preferences and a coefficient of risk aversion $\rho_{n}$ such that

$$
u_{n}(c)=-e^{-\rho_{n} c}
$$

Like the local copper producers, these agents also trade for hedging reasons, but unlike the locals they are subject to a supply shock $n \sim N\left(0, \sigma_{n}^{2}\right)$, the realization of which is known only to themselves. The shock is realized at $t=0$. The consumption of these noise traders is thus $c_{n}=n P+\pi_{n}$. Given their demand $m_{n}$ for pesos, trading profits are

$$
\pi_{n}=m_{n}(P-Q)
$$

Note that, in our setting, the term "noise" does not imply irrationality but simply the need to hedge an endowment shock by taking a market position; see Spiegel and Subrahmanyam (1992).

We turn, now, to a more detailed description of the price-formation mechanism. As already noted, prices may be determined either by profit-oriented dealers or through central bank intervention. In either case, the quoted exchange rate may be reduced to a policy function

$$
Q=\mu_{P}+\lambda \cdot\left(m-\mu_{m}\right), \quad m=m_{s}+m_{h}+m_{n},
$$

where $m$ is the order flow of market orders (for pesos) submitted, in aggregate, by speculators, local producers and noise traders. Here $\mu_{m}$ is the unconditional mean of $m$; linearity is discussed shortly. Under all exchange-rate regimes, the equilibrium is defined as follows

Definition 1 Regardless of the exchange-rate regime, a (Nash) equilibrium is a combination of market orders $m_{s}$ (given the privately observed $s$ ), $m_{n}$ (given the privately

\footnotetext{
${ }^{15}$ We use the term "precision" loosely - not in its strict statistical definition.
} 
observed $n$ ) and $m_{h}$ that are best responses given the commonly known $\lambda$.

The various exchange-rate regimes differ by $\lambda$, the sensitivity of the price to order flow. The inverse of $\lambda$ can be interpreted as a measure of liquidity: when liquidity $\lambda^{-1}$ is high, large orders can be executed with relatively small price impact. By a free-float exchangerate regime we mean that the central bank does not intervene with the operation of the profit-motivated dealers. The dealers observe the order flow (but not its components!), and quote a price. Since all other players are restricted to market orders that need to be submitted before the price is quoted, no player but the dealers can condition trading on the aggregate order flow. We follow the usual formalization by which the risk-neutral dealers quote a price equal to the expected spot price of copper (at $t=2$ ), so that the conditional expected trading profit is equal to zero. ${ }^{16}$ Alternatively, the central bank may take control of the market and operate it for social welfare rather than commercial motives, imposing its own trading policy on the dealers. Under a fixed peg, the exchangerate is set independently of the realization of order flow. In a managed float, the central bank appreciates (depreciates) the peso when it observes a strong (weak) demand, but not to the same extent as profit-oriented dealers would. More formally, we have the following

Definition 2 There are three possible exchange-rate regimes:

1. a free-float, where $\lambda_{F}$ is consistent with $Q=E(P \mid m)$;

2. fixed peg, where $\lambda=0$;

3. managed float, where $\lambda \neq \lambda_{F}$ and $\lambda>0$.

As already noted, we are aware that, in reality, central banks trade against their own portfolio rather than impose a trading policy on FX dealers. This formalization reflects

\footnotetext{
${ }^{16}$ The Kyle (1985) model is often interpreted as having a single market maker on which a "market efficiency" (zero expected profit) condition is imposed. However, a competitive-industry interpretation is offered by Kyle himself: "we could, however, replace the market efficiency condition ... with an explicit Bertrand auction between at least two risk-neutral bidders, each of whom observes the order flow ... and nothing else" (p . 1318).
} 
our preference for a clean welfare accounting at the expense of a realistic description of intervention. We think of the central bank as a public intermediary, which has no riskbearing capacity of its own. Thus, were it to trade on its own portfolio, some agents would have to bear the uncertain return on that portfolio. Essentially, the current formalization allocates all the uncertainty to the dealers, which is socially efficient owing to the dealers' risk neutrality and their infinite risk-bearing capacity.

We evaluate the policy by a standard welfare economics criterion: namely, both dealers and local producers are made (weakly) better off by the policy. Since the dealers are risk neutral, the central bank need not compensate them for bearing a higher risk. However, should the dealers bear trading losses due to the imposed policy, the central bank would compensate them (in expectation) via a lump-sum transfer funded by a tax that is levied on the local producers. Hence,

Definition 3 An exchange-rate policy $\lambda \neq \lambda_{F}$ is said to be welfare improving if the local producers are better off after paying a lump-sum transfer $T$ to the dealers such that dealers are kept at zero profit. The lump-sum tax takes place at $t=0$.

Note that the speculators and noise traders are left out of welfare accounting by virtue of their foreign status.

It is worth making two additional points about the setting. First, we assume that exchange-rate management is delegated to an independent central bank that can commit to execute the policy as intended. ${ }^{17}$ Observe that removing the commitment assumption would affect our equilibrium but would not reverse the results. Without commitment, the model would have an equilibrium where the exchange-rate policy is selected only after the order flow is observed, in a way that is foreseen by all traders when market orders are submitted. In such a case, the government may still try to improve interim (rather than ex ante) risk sharing. Clearly, the loss of commitment would limit the scope for welfare-improving exchange-rate policies. In that respect, one should interpret

\footnotetext{
${ }^{17}$ There is some evidence that central banks can better commit relative to governments; see Alesina and Summers (1993).
} 
our results as establishing a limiting case for what policy may achieve under the most favorable political assumptions.

Second, it is also noteworthy that we have implicitly assumed that all players in the model are free from insolvency constraints. Their pockets are deep enough to bear any trading losses that might occur. Needless to say, this assumption is made more for tractability than for realism. As for the government, its freedom from wealth constraints is a function of the assumed ability to levy lump-sum taxes. Evidently, our assumption is diametrically opposed to the standard assumption in the bank-run literature, where a shortage of even a small amount of liquidity may bring the system down; see Krugman (1979) and many others. It seems that both assumptions are equally extreme and call for modification in the shape of a convex "cost of maintaining the system" function, as in Morris and Shin (1998).

\section{A Free-Float Exchange Rate Regime}

In this section we consider the case of a free-float exchange-rate regime. We analyze the conditions under which equilibrium exists and highlight some key properties of that equilibrium, which provides the foundation for our analysis of welfare-improving policies in the next section.

As already noted, we analyze a Nash equilibrium of the following game. All agents are rational. Speculators receive private information and then submit a market order that maximizes expected profits, given the trading strategies of all other agents, including the dealers' pricing policy. Noise traders act in a similar way, except their trading is conditioned upon their endowment shock. Local producers trade unconditionally (copper output is deterministic), but their trading decision still relies on their expectations about how other agents would trade upon the signals that the hedgers themselves cannot observe. The dealers observe the total order flow, extract the information it contains and set prices equal to the conditional expected price of copper at $t=2$.

In line with the existing literature, we restrict attention to linear equilibria. This 
means that dealers, speculators, and noise traders all have linear strategies with respect to the signals mentioned in the previous paragraph. Note, however, that linearity is not a restriction on the strategy space: under the assumption of normal distributions and CARA utility functions and given that other agents play a linear strategy, the best response for any agent is linear as well. Thus, a linear equilibrium would survive even without the linearity assumption; however, the existence of a unique linear equilibrium does not rule out the existence of some other non-linear equilibria. We are not aware of any nonlinear equilibrium ever discussed in the literature in relation to this class of models.

It thus follows that all traders rationally foresee that the dealers price the peso according to the function

$$
E(p \mid m)=\lambda_{F}\left(m-\mu_{m}\right)
$$

As we shall see, $E\left(m_{s}\right)=E\left(m_{n}\right)=0$; since the local producers' demand is nonrandom, the mean order flow $\mu_{m}$ equals the $m_{h}$, so that

$$
m-\mu_{m}=m_{s}+m_{n}
$$

Denote by $m_{i}$ the demand for pesos by the $i$ th individual speculator, so that $m_{s}=$ $\sum_{i} m_{i}$. Denote by $m_{-i}$ the aggregate market order of all speculators less the $i$ th speculator. Then, using equation (3), the maximization problem of the $i$ th speculator is

$$
\max _{m_{i}} m_{i} \cdot E(p-q \mid s)
$$

where $q=Q-\mu_{P}$ and $\mu_{P}$ cancels out. Using equations (4), (7), and (9), and also noting that $E\left(m_{n}\right)=0$, equation (10) boils down to

$$
\max _{m_{i}} m_{i} \cdot\left[\theta s-\lambda\left(m_{i}+m_{-i}\right)\right]
$$

Assuming that all $N$ speculators are symmetric, the solution to this optimization problem is given by

$$
m_{i}=\frac{\theta}{\lambda(N+1)} s, \quad m_{s}=\delta s,
$$


and

$$
\delta=\frac{\theta N}{\lambda(N+1)} .
$$

By a similar argument and using (5), we calculate the demand for pesos by the noise traders. Owing to CARA preferences and the normality assumption, the noise traders' problem can be written using the certainty equivalence of expected utility:

$$
\max _{m_{n}} E\left(c_{n}\right)-\frac{1}{2} \rho_{n} \cdot \operatorname{Var}\left(c_{n}\right)
$$

This can be written as

$$
\max _{m_{n}}-\lambda m_{n} \bar{m}_{n}-\frac{1}{2} \rho_{n} \cdot\left\{\left[n+m_{n}(1-\lambda \delta)\right]^{2} \sigma_{p}^{2}+\left(m_{n} \lambda \delta\right)^{2} \sigma_{\varepsilon}^{2}\right\}
$$

where $m_{n}$ is the individual trader's demand for pesos and $\bar{m}_{n}$ is the demand for pesos by the entire population of noise traders. Note that the individual trader's demand is measured per unit of population, so that $m_{n}=\bar{m}_{n} \cdot{ }^{18}$ The distinction between the two numerically equal magnitudes is essential: the individual trader uses $\bar{m}_{n}$ in order to predict (rationally) the price effect of noise trading yet chooses a utility-maximizing portfolio with respect to $m_{n}$ only. Solving the portfolio problem above yields the demand for pesos by the entire population of noise traders:

$$
\begin{gathered}
m_{n}=-\delta_{n} \cdot n, \quad \delta_{n}=\frac{\rho_{n}(1-\lambda \delta) \sigma_{p}^{2}}{\lambda+\rho_{n} B}, \\
B=\left[(1-\lambda \delta)^{2} \sigma_{p}^{2}+(\lambda \delta)^{2} \sigma_{\varepsilon}^{2}\right] .
\end{gathered}
$$

Using (12), we can rewrite $B$ as

$$
B=\left(1-\theta \frac{N}{N+1}\right)^{2} \sigma_{p}^{2}+\left(\theta \frac{N}{N+1}\right)^{2} \sigma_{\varepsilon}^{2} .
$$

We can now prove the following result.

\footnotetext{
${ }^{18}$ Strictly speaking, each individual trades only a fraction $d z \rightarrow 0$, of the entire demand of the noise traders. Because they constitute a measure-1 population, aggregating over all individuals yields $m_{n}=$ $\bar{m}_{n}$. Owing to the infinitesimal size of the individual trader, there is no need to distinguish between the demand of the entire population and the demand of the entire population less the individual trader.
} 
Proposition 1 Within the class of linear equilibria, there exists a unique free-float exchangerate equilibrium if and only if

$$
K>1, \quad K=\frac{\rho_{n}^{2} \sigma_{p}^{2} \sigma_{n}^{2}\left(1-\theta \frac{N}{N+1}\right)^{2}}{\theta \frac{N}{(N+1)^{2}}} .
$$

In this equilibrium, the dealers respond to the order flow according to the coefficient

$$
\lambda_{F}=\rho_{n} B \frac{\sqrt{K}+1}{K-1} .
$$

Proof. The dealers set the exchange rate so as to break even in expectation, given the information contained in the aggregate order flow:

$$
q=E\left[p \mid m_{s}+m_{n}\right]
$$

By standard inference rules,

$$
E\left[p \mid m_{s}+m_{n}\right]=\lambda\left(m_{s}+m_{n}\right), \quad \lambda=\frac{\operatorname{Cov}\left(p, m_{s}+m_{n}\right)}{\operatorname{Var}\left(m_{s}+m_{n}\right)} .
$$

Using the result in (11), we get

$$
\lambda=\frac{\delta \sigma_{p}^{2}}{\delta^{2}\left(\sigma_{p}^{2}+\sigma_{\varepsilon}^{2}\right)+\operatorname{Var}\left(m_{n}\right)} .
$$

Note that $\lambda>0$. Hence, one may substitute for the $\delta$ as computed in equation (12) and the variance of liquidity trader demand from (13). Solving for $\lambda_{F}$ yields a quadratic equation that has one positive real root if and only if $K>1$. This root is given by (15).

Thus, a competitive equilibrium may not exist. This corresponds to the finding of Spiegel and Subrahmanyam (1992) that noise traders are willing to trade only if their demand for insurance is sufficiently high (high values of $\rho_{n}, \sigma_{p}^{2}, \sigma_{n}^{2}$ ) to justify the trading losses against informed speculators.

The properties of the free-float exchange-rate regime are crucial for the understanding of subsequent results. We elaborate on some of them, starting with the observation that - even without any state intervention - the dealers already provide some insurance to the local producers by smoothing fluctuations of the exchange rate. Our next result follows from equations (16) and (12). 
Corollary 1 Under a free-float exchange rate, dealers smooth the exchange rate so that

$$
\operatorname{Var}\left(q \mid \lambda_{F}\right)=\theta \frac{N}{N+1} \sigma_{p}^{2}<\sigma_{p}^{2}
$$

To see why smoothing the exchange rate provides insurance, note that under autarky (i.e., without any hedging, so that $m_{h}=0$ ) the local producers' exposure is determined solely by the variability of the terms of trade, $\sigma_{p}^{2}$. Under a free-float exchange-rate regime, the local producers may hedge themselves by holding the first-best portfolio $m_{h}=-Y$. But unlike the first-best equilibrium, in the present case this portfolio would not deliver full insurance because of execution risk. As noted, the local producers submit market orders, which the dealers price only after they observe the order flow, thus leaving the hedgers exposed to some price uncertainty. Still, Corollary 1 guarantees that, relative to autarky, some insurance is provided by the market. The questions of whether this is the socially optimal amount of insurance and whether there is any way for exchange-rate policy to improve upon it is obviously the main concern of our analysis.

However, under a free float, the exchange rate is determined not by risk-sharing considerations but rather by informational efficiency. As a result, from (16) we derive the next corollary

Corollary 2 A free-float exchange-rate regime is (semi-strong form) informationally efficient, so that

$$
\frac{\operatorname{Cov}\left(q, p \mid \lambda_{F}\right)}{\operatorname{Var}\left(q \mid \lambda_{F}\right)}=1
$$

Since $P$ is just the next-period value of local currency, Corollary 2 implies that given public information, the current price of local currency is the best predictor of the future price, which means semi-strong form informational efficiency. Thus, Corollary 1 may be interpreted as a Shiller (1981) variance-inequality result: since the current price predicts the future price with an error that is uncorrelated with the current price, the future price must have a variance that is greater than the current price. Hence, the fact that prices are not fully revealing plays a crucial role in delivering risk sharing in a free-float equilibrium. Corollaries 1 and 2 highlight the basic tension in our model between the 


\section{Guembel and Sussman Optimal Exchange Rates}

risk-sharing and information-efficiency role of prices. Under a free float, the dealers price the peso so as not to "leave money on the table". Any price management would create a profit opportunity for market participants and a trading loss for the dealers, for which the tax payer would have to compensate them.

For subsequent results, we derive the local producers' portfolio and welfare under a free float. Using equations (2), (7), and (9), we express their decision problem as a standard mean-variance portfolio problem with two risky assets:

$$
\begin{gathered}
\max _{m_{h}} Y \mu_{P}-\frac{1}{2} \rho_{h} \operatorname{Var}\left(c_{h}\right), \\
\operatorname{Var}\left(c_{h}\right)=\left(Y+m_{h}\right)^{2} \sigma_{p}^{2}-2\left(Y+m_{h}\right) m_{h} \sigma_{p q}+m_{h}^{2} \sigma_{q}^{2} .
\end{gathered}
$$

Using Corollary 2 we have the following.

Corollary 3 Under a free-float exchange rate, the local producers hold all their wealth in dollars,

$$
\left(m_{h} \mid \lambda_{F}\right)=-Y
$$

As hinted previously, the optimal portfolio is indeed the same as in the first best; but unlike the first best, full insurance is not obtained owing to execution risk. Substituting the local producers' portfolio (21) into their objective function (19) allows us to derive our next corollary.

Corollary 4 Under a free float exchange rate, local producer's welfare is given by

$$
\begin{gathered}
W_{F}=Y \mu_{P}-\frac{1}{2} \rho_{h} \cdot Y^{2} \cdot \operatorname{Var}\left(q \mid \lambda_{F}\right), \\
\operatorname{Var}\left(q \mid \lambda_{F}\right)=\theta \frac{N}{N+1} \sigma_{p}^{2} .
\end{gathered}
$$

We postpone complete comparative statics analysis of the free-float regime until the next section. At this point it is sufficient to remark that the local producers' welfare falls the better informed and more numerous speculators are. This result highlights the role played by the Hirshleifer effect in our model. Note that the speculators trade more aggressively the more precise their private information is (namely, the higher is 
$\theta)$ and the more numerous they are. The second effect is due to the Cournot nature of our equilibrium: the greater the number of speculators, the less they internalize the price impact of their own trading and the more aggressively they trade. As a result of both effects, the equilibrium becomes more revealing, more insurance opportunities are destroyed, and the local producers' welfare falls. ${ }^{19}$

\section{The Optimal Exchange Rate}

Under a free float, the dealers break even in expectation and the speculators' profits are all made at the expense of the noise traders. (Note that, under any $\lambda$, the local producers avoid active trading and thus any trading losses.) Once the central bank determines an exchange-rate policy that deviates from informational efficiency, this result no longer holds: the dealers would bear some trading losses, for which the central bank would have to compensate them. That would require a lump-sum tax $T$ on the local producers such that

$$
T=E\left(\pi_{n}\right)+E\left(\pi_{s}\right)
$$

Using equation (6), it is easy to see that the noise trader's profits are

$$
E\left(\pi_{n}\right)=-\lambda \delta_{n}^{2} \sigma_{n}^{2}
$$

the speculators' profits are given by

$$
E\left(\pi_{s}\right)=\frac{\theta}{\lambda} \frac{N}{(N+1)^{2}} \sigma_{p}^{2} .
$$

We can now derive the following result.

Proposition 2 A fixed exchange-rate regime $(\lambda=0)$ is not feasible.

\footnotetext{
${ }^{19}$ Note, however, that this result relies heavily on the speculators' risk neutrality; otherwise, an increased number of speculators would increase the risk-bearing capacity of the market. It is also worth emphasizing again that this result might depend on the CARA specification of locals' and noise traders' risk aversion.
} 
Guembel and Sussman Optimal Exchange Rates

Proof. Using equations (13), (25), and (26), it is easy to verify that

$$
\lim _{\lambda \rightarrow 0} T=\infty
$$

As emphasized in the previous section, when exchange-rate policy deviates from a free float, prices are informationally inefficient and some money is left on the table. However, only the speculators can take advantage of that situation. This is because uninformed agents are not allowed to condition trading on the exchange rate and to profit thereby from informationally inefficient pricing of the peso. To better understand this statement, note that, whenever $\lambda \neq \lambda_{F}$, the peso may be either overvalued or undervalued. Moreover, observing a price and knowing both the policy $\lambda$ and the informationally efficient pricing rule $\lambda_{F}$, agents can figure out whether the price is above or below the informationally efficient price. If they were able to condition their trading on that information, they could profit by going long (short) on the peso when it is undervalued (overvalued). However, since they are restricted to market orders that must be submitted before the price is announced, uninformed agents cannot take advantage of the informational inefficiency. ${ }^{20}$ In contrast, speculators (who are restricted to the same "trading technology" as other agents), can use their private information to forecast mispricing of the peso, take the right position, and make a profit. Obviously, the prospects for speculative profits increase as the exchange-rate becomes smoother and the central bank forces the dealers to absorb the order flow with a smaller price adjustment. Since the speculators are risk neutral, they can trade very aggressively. At the limit, when the exchange rate is pegged, their trading profits tend to infinity; see equation (12). Note, however, that the argument here is not symmetric, and that speculative profits vanish as $\lambda \rightarrow \infty$. This is because, when faced with a more price-responsive policy, the oligopolistic dealers must consider the greater price impact that their own trading has on the market and hence scale back their trading.

\footnotetext{
${ }^{20} \mathrm{An}$ alternative formalization that would limit noise traders' ability to speculate is price-conditional trading (possibly via limit orders) and an additional noise term.
} 
Things are quite different for the noise traders. Facing the same endowment shock, noise traders also have some information about mispricing. However, they cannot take advantage of it because of risk aversion, which generates a hedging motive to trade in the opposite direction from the speculative motive. To see why, consider a positive endowment shock that would induce them to take a short position in the peso. Hence, they expect a low order flow that would induce the dealers devalue the peso. Knowing that the devaluation is not an indication of bad news, the noise traders may speculate by going long on the peso, against their own hedging motive. As a result, the noise traders can never profit from trading; see equation (25). Their trading losses, unlike those of the speculators, are zero at a fixed peg because the exchange rate never deviates from the unconditional mean price of copper. ${ }^{21}$

Let us now turn to the complete social welfare analysis. The idea is to recover some of the insurance opportunities destroyed by the Hirshleifer effect and to compensate dealers for the trading losses. The compensation is funded by an ex ante lump-sum tax on the local producers. Our objective function is thus

$$
W=Y \mu_{P}-T-\frac{1}{2} \rho_{h} \cdot \operatorname{Var}\left(c_{h}\right)
$$

We can now prove the main result of this paper.

Proposition 3 Suppose that $K>1$ (a free-float equilibrium exists). Then (i) the social welfare optimization problem has an interior solution $0<\lambda^{*}<\infty$, and (ii) the free-float equilibrium is generically inefficient $\left(\lambda^{*} \neq \lambda_{F}\right)$.

Proof. We start with part (i) of the proposition. Proposition 2 has already demonstrated that $\lambda^{*} \neq 0$. To prove that $\lambda^{*}<\infty$, we show that $\partial W / \partial \lambda<0$ for high $\lambda$.

There are two channels through which $\lambda$ affects welfare: risk exposure and the tax burden; see equation (27). Starting with the first effect, we note that $\operatorname{Cov}(p, q)$ is inde-

\footnotetext{
${ }^{21}$ At the other end, when $\lambda$ is high, trading profits also tend to zero as the trading intensity of the noise traders approaches zero; see equation (13).
} 
pendent of $\lambda$ :

$$
\operatorname{Cov}(p, q)=\lambda \delta \sigma_{p}^{2}=\theta \frac{N}{N+1} \sigma_{p}^{2}
$$

Applying the envelope theorem to equation (19) allows us to derive

$$
\frac{d \operatorname{Var}\left(c_{h}\right)}{d \lambda}=m_{h} \cdot \frac{d \operatorname{Var}(q)}{d \lambda}
$$

Now

$$
\operatorname{Var}(q)=\theta \frac{N^{2}}{(N+1)^{2}} \sigma_{p}^{2}+\left(\lambda \delta_{n}\right)^{2} \sigma_{n}^{2}
$$

Using this and equation (13), it is easy to verify that

$$
\frac{d \operatorname{Var}\left(c_{h}\right)}{d \lambda}>0
$$

Next, we use equations $(24)-(26)$ to calculate the effect of $\lambda$ on the tax:

$$
-\frac{d T}{d \lambda}=\theta \frac{N}{\lambda^{2}(N+1)^{2}} \sigma_{p}^{2}+\frac{\rho_{n} B-\lambda}{\left(\lambda+\rho_{n} B\right)^{3}} \rho_{n}^{2} \sigma_{p}^{4} \sigma_{n}^{2}\left(1-\theta \frac{N}{N+1}\right)^{2} .
$$

Hence, $-\partial T / \partial \lambda<0$ whenever

$$
K \frac{\lambda^{3}}{\left(\lambda+\rho_{n} B\right)^{3}}>1+\frac{\lambda^{2} \rho_{n} B(N+1)^{2}}{\left(\lambda+\rho_{n} B\right)^{3} \theta N} .
$$

As $\lambda \rightarrow \infty$ and whenever $K>1$, inequality (32) is satisfied. Hence, at high $\lambda, \partial T / \partial \lambda>0$ so that increasing $\lambda$ requires a higher tax. ${ }^{22}$ It follows that, for sufficiently high $\lambda$,

$$
\frac{\partial W}{\partial \lambda}=-\frac{\partial T}{\partial \lambda}-\frac{\rho_{h}}{2} \frac{\partial \operatorname{Var}\left(c_{h}\right)}{\partial \lambda}<0
$$

and hence $\lambda^{*}$ must be internal.

In order to prove part (ii) of the proposition, we evaluate the two effects identified previously at the free-float point. Starting with equation (29) we get

$$
\left.\frac{d \operatorname{Var}\left(c_{h}\right)}{d \lambda}\right|_{\lambda=\lambda_{F}}=\left.Y^{2} \cdot \frac{d \operatorname{Var}(q)}{d \lambda}\right|_{\lambda=\lambda_{F}} .
$$

Differentiating equation (30) and evaluating the derivative at the free-float point yields

$$
\left.\frac{d \operatorname{Var}(q)}{d \lambda}\right|_{\lambda=\lambda_{F}}=2 \lambda_{F} \delta_{n} \sigma_{n}^{2}\left(\left.\lambda \frac{d \delta_{n}}{d \lambda}\right|_{\lambda=\lambda_{F}}+\delta_{n}\right)>0
$$

\footnotetext{
${ }^{22}$ However, the level of the tax tends to zero as both noise and speculators' profits tend to zero; see equations (25) and (26).
} 
Again using equations (24) - (26) we differentiate the tax function and evaluate the derivative at the free-float point (where, by informational efficiency, $T=0$ ), so that

$$
\left.\frac{d T}{d \lambda}\right|_{\lambda=\lambda_{F}}=-2 \delta_{n} \sigma_{n}^{2}\left(\left.\lambda \frac{d \delta_{n}}{d \lambda}\right|_{\lambda=\lambda_{F}}+\delta_{n}\right)<0 .
$$

Clearly, it is optimal for the bank to intervene in the FX market whenever

$$
-\left.\frac{d T}{d \lambda}\right|_{\lambda=\lambda_{F}}-\left.\frac{1}{2} \rho_{h} Y^{2} \cdot \frac{d \operatorname{Var}(q)}{d \lambda}\right|_{\lambda=\lambda_{F}} \neq 0 \Longleftrightarrow 1-\frac{1}{2} \rho_{h} Y^{2} \lambda_{F} \neq 0 .
$$

Since $\lambda_{F}$ is a combination of the external parameters (see Proposition 1), it is clear from (36) that the condition for intervention is generically satisfied.

Parallel to the dual role of prices (informational efficiency and risk-sharing), Proposition 3 identifies two motives for intervention: the revenue motive (see equation (35)) and the insurance motive (see equation (33)). The risk-sharing motive always motivates the bank to smooth the exchange rate. However, such a policy also generates trading losses, at least at the free-float point. Clearly, one of the fundamental insights of our paper is the understanding that the two effects operate in opposite directions. Central banks are constantly searching for a policy that would both deter speculation and smooth prices. Proposition 3 suggests that perhaps both objectives cannot be achieved simultaneously.

Another implication of Proposition 3 is that only by coincidence will the optimal trade-off occur at the free-float $\lambda_{F}$. This result should be clear by now: free-float exchange rates are determined by informational efficiency. If markets are incomplete and local producers cannot hedge against terms-of-trade uncertainty, then there is no reason to suppose that laissez-faire is socially optimal. Going back to Proposition 2, it is also clear that a fixed peg is not even feasible, let alone optimal. In that respect, neither corner solutions has any attractive welfare properties.

Since it is not clear which motive for intervention dominates, it must be theoretically possible for the smoothing policy to be reversed. This means that the bank would increase price responsiveness so as make a trading profit, which would be allocated back to the local producers via a lump-sum transfer. Effectively, the central bank would coordinate the dealers into a monopoly that extracts rent from the noise traders who wish to use 
the peso for hedging purposes. Note that, in such a case, the speculators' profits would decrease although their trading profits would remain positive.

One might expect that, in a model with so many distribution effects, figuring out what direction the policy should operate in would be very complicated. However, the problem is helped by the extremely simple form that the trade-off between FX variance and the tax takes at the free-float equilibrium. From equations (35) and (34) we can derive how exchange rate volatility can be traded off against the dealers' trading losses:

$$
\frac{d T}{d \operatorname{Var}(q)_{\lambda_{F}}}=-\frac{1}{\lambda_{F}}
$$

A marginal reduction in exchange-rate variance increases trading losses by a factor $\lambda_{F}^{-1}$, which is a measure of liquidity. The more liquid the market is (lower $\lambda_{F}$ ), the less favorable the trade-off between smoothing and taxation becomes. Intuitively, this happens because speculators trade larger sizes when markets are more liquid. Any arbitrage opportunities that arise from a smoothing policy therefore incur a trading loss proportional to the speculators' trading intensity. The optimal policy needs to balance these two effects. Using the equalities $\left.m_{h}\right|_{\lambda=\lambda_{F}}=\left.\mu_{m}\right|_{\lambda=\lambda_{F}}=Y$ and $\mu_{q}=\mu_{p}$, the condition in equation (36) can be expressed as the following simple rule of thumb.

Corollary 5 It is optimal to smooth the exchange rate by setting $\lambda$ below $\lambda_{F}$ if and only if

$$
\left[\frac{1}{2} \rho_{h}\left(Y \mu_{p}\right)\right] \cdot\left(\lambda_{F} \frac{\mu_{m}}{\mu_{q}}\right)>1,
$$

where the first term on the left is (half) the local producers' relative risk aversion and the second is the elasticity of the exchange rate with respect to the order flow under free float.

As one would expect, smoothing is optimal if the local producers are relatively risk averse. Corollary 5 highlights another important insight: that the scope for exchangerate management depends on the economy's financial structure. Thus, exchange-rate policy may increase welfare in economies where the free-float equilibrium exchange rate is highly elastic with respect to the order flow - that is when the free float liquidity parameter $\lambda_{F}^{-1}$ is low. To see what type of economies are likely to satisfy this condition, we 
analyze how the free-float elasticity $\lambda_{F}$ is affected by the model's exogenous parameters. In order to facilitate the interpretation, we regroup the parameters into economically more meaningful composite variables and take partial derivatives with respect to each such variable. In particular, (15) can be rewritten as a function of the following five (composite) variables: noise traders' risk aversion $\rho_{n}$, the relative size of noise traders' endowments shocks $\sigma_{n}^{2} /\left(\sigma_{p}^{2}+\sigma_{\varepsilon}^{2}\right)$, the overall level of uncertainty in the economy $\sigma_{p}^{2}+\sigma_{\varepsilon}^{2}$, the speculators' information quality $\theta$, and the number $N$ of speculators.

Proposition 4 The partial effect of the model's parameters on the free-float elasticity of the exchange rate $\lambda_{F}$ with respect to order flow is given as follows.

\begin{tabular}{|c|c|c|c|c|}
\hline$\rho_{n}$ & $\frac{\sigma_{n}^{2}}{\sigma_{p}^{2}+\sigma_{\varepsilon}^{2}}$ & $\sigma_{p}^{2}+\sigma_{\varepsilon}^{2}$ & $\theta$ & $N$ \\
\hline \hline- & - & - & \pm & \pm \\
\hline
\end{tabular}

Moreover, if $\theta<(N+1)^{2} /[2 N(2+N)]$ then $d \lambda_{F} / d \theta>0$.

Proof. See the Appendix.

Consider first an increase in $\rho_{n}$. When the noise traders become more risk averse, they increase their trading intensity as they become more eager to hedge their positions. When the dealers realize that a larger part of the order flow is driven by hedging needs rather than by informed speculation, they absorb it with a smaller price effect and the free-float liquidity $\lambda_{F}^{-1}$ increases. In such circumstances, the dealers provide more insurance and there is less need for exchange-rate smoothing. Similarly, equilibrium liquidity increases ( $\lambda_{F}$ falls) when the relative size of the noise traders' endowment shock, $\sigma_{n}^{2} /\left(\sigma_{p}^{2}+\sigma_{\varepsilon}^{2}\right)$ increases.

Consider next the partial effect of $\sigma_{p}^{2}+\sigma_{\varepsilon}^{2}$. Since the signal precision $\theta$ is held constant, the relative magnitude of $\sigma_{p}^{2}$ and $\sigma_{\varepsilon}^{2}$ remains the same. Moreover, $\sigma_{n}^{2}$ is increased by the same proportion as $\sigma_{p}^{2}+\sigma_{\varepsilon}^{2}$ so as to keep the relative magnitude of the two variances constant. Effectively, $\sigma_{p}^{2}+\sigma_{\varepsilon}^{2}$ therefore measures the economy's overall level of uncertainty.

To better appreciate the partial effect, observe that date-1 FX trading can be interpreted in our model as pure "capital flows" (issuing the contracts) whereas date-2 
flows are a mix of the capital account (settling the contracts issued in the previous period) and the current account (delivering copper and purchasing the consumption goods). Thus $\sigma_{p}^{2}+\sigma_{\varepsilon}^{2}$ and $\sigma_{n}^{2}$ measure the variability of the exogenous shocks underlying capital flows; the larger is the level of these variances, the higher is the volume of capital-flow fluctuations. This explains the negative partial effect of the level of uncertainty on the equilibrium $\lambda$ : as a given amount of information is incorporated into prices via a higher volume, the marginal effect of order flow on the exchange rate becomes smaller. Note, however, that even though $\lambda$ falls, the volatility of the exchange rate increases and welfare falls (see Corollary 4). Yet it is "less likely" that a smoothing policy could improve welfare, because the trading losses against higher-volume capital-flow fluctuations would increase.

The effect of increased signal precision $\theta$ is roughly opposite that of $\rho_{n}$ : the order flow becomes more informative and the dealers absorb it with greater price sensitivity. Moreover, note that the speculators' trading intensity responds equally to changes in $\theta$ and $N /(N+1)$ (see equation (12)). Nevertheless, the equilibrium effect of the latter variable is quite different. To understand why, consider equation (17), which shows that the first-order effect of $\theta$ on $\lambda$ is positive while the effect of $N /(N+1)$ is nonmonotonic. ${ }^{23}$ The economic interpretation is as follows: When the speculators become more numerous, they trade more aggressively on both the information and the noise component of their signal; it is hence unclear whether order flow becomes more or less informative. This is different when signal precision increases and therefore more information is incorporated into order flow. In that case, dealers price the peso with greater sensitivity to order flow. However, noise traders also change their trading intensity when prices becomes more informative, which is why the comparative static with respect to $\theta$ and $N$ remains ambiguous. As Figure 1 shows, the effects just described interact in a complicated way, which makes it difficult to derive analytic results regarding $N$. However, most simulations

\footnotetext{
${ }^{23}$ Dividing both numerator and denominator of (17) by $\sigma_{p}^{2}+\sigma_{\varepsilon}^{2}$, note that $\theta$ appears in both in a squared form, whereas $N /(N+1)$ appears linearly in the numerator but squared in the simulation. In the figure we have set $\rho_{n}=1, \sigma_{p}^{2}+\sigma_{\varepsilon}^{2}=1, \sigma_{n}^{2} /\left(\sigma_{p}^{2}+\sigma_{\varepsilon}^{2}\right)=1$.
} 
Guembel and Sussman Optimal Exchange Rates

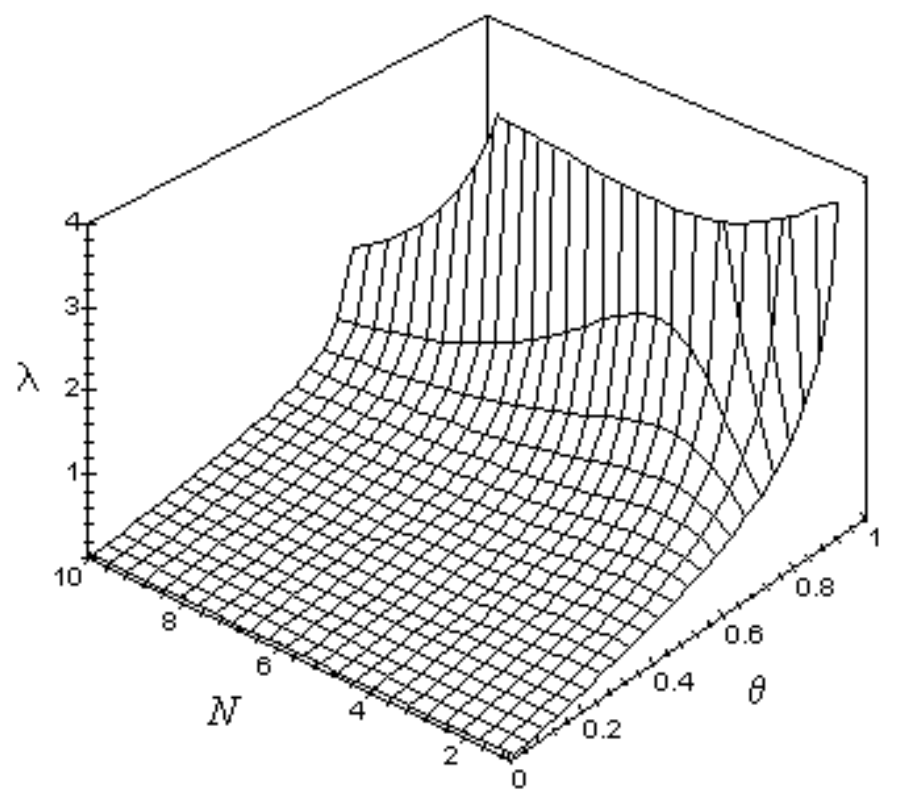

Figure 1: $\lambda$ as a function of $\theta$ and $N$ (see note 24 ).

that we have conducted "look similar" to Figure $1 .^{24}$ In particular, we find that $d \lambda_{F} / d \theta>$ 0 for a wide range of parameter values, even when the sufficient condition of Proposition 4 is violated.

Thus, exchange-rate smoothing "is more likely" to add welfare in economies where (a) a relatively small fraction of foreign trading in the local currency is driven by hedging needs, (b) speculators are relatively few and command good insider knowledge of the sort of news that moves the exchange rate, (c) capital flows are of a moderate volume. All these conditions seem to be satisfied in illiquid FX markets, most likely in small economies or emerging markets.

\section{The Tobin Tax}

In addition to direct intervention in the FX market, the central bank may be able to affect exchange-rate fluctuations via a Tobin tax. The practical feasibility of enforcing such a tax in a world where millions of dollars can be moved across borders within seconds is

\footnotetext{
${ }^{24}$ High values of $\theta$ and $N /(N+1)$ may violate the $K>1$ condition for existence; we have truncated such values from the picture.
} 
obviously questionable. But given the broad attention that the Tobin tax has received in the literature, the analysis is interesting even as a theoretical exercise. Another reason to analyze the Tobin tax is for its role in an alternative interpretation of the results, which is offered in the next section.

A Tobin tax serves two functions. First, it discourages speculation and so in our setting would have a direct stabilizing effect. Second, it generates revenue. Revenue is generated both directly and (much more importantly) indirectly by decreasing the dealers' losses to the speculators while implementing a smoothing policy. Since these trading losses are a major obstacle to implementing an exchange-rate policy, the Tobin tax plays an important role in enabling exchange-rate management. Indeed, the first main result of this section is that a fixed peg, which was previously shown to be infeasible, becomes feasible once accompanied by a Tobin tax. Note, however, that while the tax discourages speculation it also has a distortive effect, as it increases the cost of hedging for local producers. It is thus not a priory clear that overall a Tobin tax would improve welfare. Hence our second main result is to provide a sufficient condition to that effect.

Suppose that the central bank can levy a nonlinear tax on FX transactions; more specifically, assume that the tax is quadratic in the order flow of each trader and equals $(1 / 2) \tau m^{2}$. The assumption is made for tractability, so as to preserve linearity at the margin (see Subrahmanyam 1998; Dow and Rahi 2000). Clearly, the nonlinearity of the tax exacerbates the implementability problem. Traders have an incentive to split orders, infinitesimally, in order to avoid the tax. However, it should be noted that the nonlinearity does not play any economically meaningful role in the analysis. At least intuitively, the argument relies only on a wedge that is inserted between the market price and the effective price of the peso.

As for the fiscal effect of the tax, the lump-sum tax $T$ that must be levied on the domestic producers is given by

$$
T=E\left(\pi_{n}\right)+E\left(\pi_{s}\right)-\frac{1}{2} \tau E\left(N m_{i}^{2}+\bar{m}_{h}^{2}+\bar{m}_{n}^{2}\right)
$$

where $\bar{m}_{h}$ and $\bar{m}_{n}$ are aggregate positions (to be distinguished from decision variables). 
Thus, the lump-sum tax equals the trading losses minus the tax revenue from a Tobin tax. We can now follow the same steps as in the previous section to show the following.

Proposition 5 A Tobin tax $\tau>0$ enables a policy of a fixed exchange rate.

Proof. In the presence of a Tobin tax, the speculator's optimization problem can be rewritten as

$$
\max _{m_{i}} m_{i} \cdot\left[\theta s-\lambda\left(m_{i}+m_{-i}\right)\right]-\frac{1}{2} \tau m_{i}^{2}
$$

Solving for the equilibrium $m_{i}$ yields

$$
m_{i}=\frac{\theta}{\lambda(N+1)+\tau} s, \quad m_{s}=\delta s, \quad \delta=\frac{\theta N}{\lambda(N+1)+\tau} .
$$

For $\tau>0, \delta$ is therefore bounded above for $\lambda=0$. Hence, $E\left(\pi_{s}\right)$ is also bounded. Moreover, it is straightforward to show that all other terms in equation (38) are finite at $\lambda=0$, and hence $T$ is finite also.

Thus, a policy that was previously not feasible because of speculation is now enabled by the Tobin tax, which decreases the intensity of all FX trading. It should be clear, however, that the result does not mean that a fixed exchange rate is optimal. Moreover, since the Tobin tax also decreases the intensity of noise trading, it is not even clear what effect it would have on exchange-rate volatility. We thus turn to the complete welfare analysis.

Given the Tobin tax, the optimization problem of the local producers can be written as

$$
\max _{m_{h}} Y \mu_{P}-T-\frac{1}{2} \tau m_{h}^{2}-\frac{1}{2} \rho_{h} \operatorname{Var}\left(c_{h}\right)
$$

Straightforward calculations yield

$$
m_{h}=-Y \frac{\rho_{h}(1-\lambda \delta) \sigma_{p}^{2}}{\tau+\rho_{h}\left[(1-\lambda \delta)^{2} \sigma_{p}^{2}+(\lambda \delta)^{2} \sigma_{\epsilon}^{2}+\left(\lambda \delta_{n}\right)^{2} \sigma_{n}^{2}\right]}
$$

or

$$
m_{h}=-Y \frac{\rho_{h}(1-\lambda \delta) \sigma_{p}^{2}}{\tau+\rho_{h}\left[(1-\lambda \delta) \sigma_{p}^{2}+\left(\lambda / \lambda_{F}\right) \lambda \delta \sigma_{p}^{2}\right]} .
$$


Thus, the tax has a clear distortive effect as it decreases the amount of hedging by the local producers (at the free-float point). ${ }^{25}$ The tax would have a similar effect on the noise traders. Nevertheless, consumption variance of the local producers falls, since the decrease in speculative trading has a stronger effect on exchange-rate volatility (at any given $\lambda$ ). Our next lemma makes this more precise.

Lemma 1 A small Tobin tax reduces risk exposure:

$$
\left.\frac{d \operatorname{Var}\left(c_{h}\right)}{d \tau}\right|_{\tau=0}<0
$$

Proof. Using equation (41) allows us to write

$$
\begin{aligned}
\left.\frac{d \operatorname{Var}\left(c_{h}\right)}{d \tau}\right|_{\tau=0} & =\left.2 \frac{d \delta}{d \tau}\right|_{\tau=0} \cdot\left\{-m_{h} \lambda \sigma_{p}^{2}\left[Y+m_{h}(1-\lambda \delta)\right]+m_{h}^{2} \lambda^{2} \sigma_{\epsilon}^{2} \delta\right\} \\
& +\left.2 \frac{d \delta_{n}}{d \tau}\right|_{\tau=0} m_{h}^{2} \lambda^{2} \sigma_{n}^{2} \delta_{n}
\end{aligned}
$$

Using (39) allows the further simplification

$$
\begin{aligned}
\left.\frac{d \operatorname{Var}\left(c_{h}\right)}{d \tau}\right|_{\tau=0} & =2 m_{h} \theta \frac{N}{\lambda(N+1)^{2}} \cdot\left\{\sigma_{p}^{2}\left[Y+m_{h}(1-\lambda \delta)\right]-m_{h} \theta \frac{N}{N+1} \sigma_{\epsilon}^{2}\right\} \\
& -\frac{2 m_{h}^{2} \lambda^{2} \sigma_{n}^{2} \delta_{n}^{2}}{\lambda+\rho_{n} B} .
\end{aligned}
$$

Substituting in the optimal hedging demand from (41) enables us to show that

$$
\sigma_{p}^{2}\left[Y+m_{h}(1-\lambda \delta)\right]-m_{h} \theta \frac{N}{N+1} \sigma_{\epsilon}^{2}>0
$$

Given that $m_{h}<0$, it follows that

$$
\left.\frac{\partial \operatorname{Var}\left(c_{h}\right)}{\partial \tau}\right|_{\tau=0}<0
$$

It is useful to integrate this result with those of the previous section. Using Lemma 1 and the analysis of the partial effect of $\lambda$ on $\operatorname{Var}\left(c_{h}\right)$ in Proposition 3, we conclude that consumption variance can be reduced under a small Tobin $\operatorname{tax} \tau$ or exchange-rate smoothing (or both). Combining the tax burden of the Tobin tax with its effect on the risk exposure of local producers yields the following welfare result.

\footnotetext{
${ }^{25}$ Note that, at $\lambda=\lambda_{F}$ equation (41) is reduced to (21) as $\tau \rightarrow 0$.
} 
Proposition 6 A small Tobin tax may be welfare increasing. A sufficient (but not necessary) condition for welfare improvement is $N<4$ and $\lambda<\left(\rho_{n} / 3\right) B$.

Proof. In the presence of a Tobin tax, the welfare function can be written as

$$
W=Y \mu_{P}-T-\frac{1}{2} \tau m_{h}^{2}-\frac{1}{2} \rho_{h} \cdot \operatorname{Var}\left(c_{h}\right) .
$$

Taking the first-order condition with respect to $\tau$ and applying the envelope theorem, we have

$$
\left.\frac{d W}{d \tau}\right|_{\tau=0}=-\left.\frac{d T}{d \tau}\right|_{\tau=0}-\frac{1}{2} m_{h}^{2}-\left.\rho_{h} \frac{d \operatorname{Var}\left(c_{h}\right)}{d \tau}\right|_{\tau=0} .
$$

Given equations (38) and (39), we can evaluate the derivative at $\tau=0$

$$
\begin{gathered}
\left.\frac{d W}{d \tau}\right|_{\tau=0}=-\left[-\theta \frac{3 N}{2 \lambda^{2}(N+1)^{2}}+2 \theta \frac{N^{2}}{\lambda^{2}(N+1)^{3}}\right] \sigma_{p}^{2} \\
+\frac{1}{2} \delta_{n}^{2} \sigma_{n}^{2}\left(1-4 \frac{\lambda}{\lambda+\rho_{n} B}\right)-\left.\rho_{h} \frac{d \operatorname{Var}\left(c_{h}\right)}{d \tau}\right|_{\tau=0} .
\end{gathered}
$$

Since

$$
\left.\frac{d \operatorname{Var}\left(c_{h}\right)}{d \tau}\right|_{\tau=0}<0
$$

a sufficient condition for a welfare improvement is that net revenue $(-T)$ minus the Tobin tax paid by the local producers $(1 / 2)\left(\tau m_{h}^{2}\right)$ be nondecreasing in $\tau$. This is the case when

$$
-\left[-\theta \frac{3 N}{2 \lambda^{2}(N+1)^{2}}+2 \theta \frac{N^{2}}{\lambda^{2}(N+1)^{3}}\right] \sigma_{p}^{2}+\frac{1}{2} \delta_{n}^{2} \sigma_{n}^{2} \frac{\rho_{n} B-3 \lambda}{\lambda+\rho_{n} B}>0 .
$$

A sufficient condition for this to be true is $N<4$ and $\lambda<\left(\rho_{n} / 3\right) B$.

Note that the proof (particularly equation (42)) provides a sufficient condition under which the total required tax payment, $T+(1 / 2) \tau m_{h}^{2}$, decreases in the Tobin tax (note that the revenue effect of $(1 / 2) \tau m_{h}^{2}$ is neutral because it reduces $T$ by an equal amount). Under the sufficient condition in Proposition 6, a small positive $\tau$ would improve welfare as both consumption variance and the tax burden fall.

More generally, an optimal policy may involve the smoothing of the exchange rate combined with a small Tobin tax. We know from Proposition 3 that the tax burden $T+(1 / 2) \tau m_{h}^{2}$ increases when $\lambda$ falls (locally at the free float). Under the sufficient conditions identified in Proposition 6, a small Tobin tax can generate revenue and reduce 
consumption variance. Essentially, the negative fiscal effect of a smoothing policy can be mitigated by a Tobin tax, which would generate revenue directly, decrease the trading losses to speculators, and reduce risk exposure.

Note, however, that the condition in Proposition 6 is weak; a Tobin tax may improve welfare even when it reduces revenue if the risk-sharing effect dominates the revenue effect. In that case a small Tobin tax could be used to reduce consumption variance, even though this would increase the tax burden when the sufficient condition in Proposition 6 is violated. In addition to using a small tax, a policy maker could increase $\lambda$ above the free-float level in order to mitigate the negative fiscal implications of the Tobin tax — at the cost of reducing its risk sharing advantages.

\section{Concluding Remarks}

The literature using a market microstructure approach to exchange-rate theory is growing fast. By and large, this literature has focused on positive aspects of exchange-rate determination, using order-flow information in order to provide a better explanation of exchange-rate movements (see Lyons 2001 for an excellent overview of the progress made so far). The use of this approach to investigate normative aspects of exchange-rate policy has been limited. In this paper we try to address this deficiency by exploring the theory's potential in shedding new light on some of the exchange-rate policy issues that have been the subject of debate at least since Friedman's (1953) contribution.

This paper provides a simple market microstructure model of exchange-rate management that allows us to identify conditions under which a smoothing policy can be welfare improving. In the discussion of Proposition 4 we show that the exogenous conditions favoring exchange-rate management are more likely to be satisfied in small and emerging markets. The argument that associates exchange-rate management with emerging markets is somewhat stronger than this and is embedded in some of our modeling assumptions. First, by disallowing trade at $t=1$, we have made the markets "very incomplete". Such a level of incompleteness is more common in emerging markets than in developed 
markets. Clearly, once insurance markets function more smoothly, the very argument for exchange-rate management collapses. Second, most emerging markets suffer from "financial repression", one symptom of which is above-normal transaction costs for any financial deal, including FX. These transaction costs have an effect similar to a Tobin tax. Such "sand in the wheels" of trade could facilitate the implementation of exchange-rate management, since it increases the cost of speculative trading.

Although our analysis is primarily normative, the implied correlation between economic development and a fear of floating the exchange rate seems to be confirmed by the data; see Calvo and Reinhart (2002). Note again that our explanation is very different than theirs and is unrelated to a commitment to avoiding inflation.

Perhaps the most important advantage of the microstructure approach is that it lends itself easily to a proper welfare analysis of exchange-rate policy, where welfare is measured just as in any other public economics exercise. Thus, for example, Friedman has posed the question of whether private speculation is "sufficiently smoothing" of the exchange rate; many have argued with his affirmative answer, but few have done so upon sound welfare economics grounds. Even when incomplete-markets models — with proper welfare measures - were used, it was difficult to relate the results to the traditional policy questions; in particular, whether the central bank should "accommodate" fluctuations in the demand for foreign currency so as to decrease the volatility of the exchange rate. The microstructure approach is able to do just that. Even if the reader disagrees with our specification of the type of players (producers, speculators, etc.), their preferences (CARA and risk neutrality), the source of risk exposure (terms of trade, endowment shocks), or financial structure (commodity money, market orders, perfectly competitive dealers), a framework is provided where the setting can be modified and the conclusions reconsidered.

Where the microstructure approach gets the extra power is from the modeling of speculation. Here, traditional approaches have either ignored the restrictions that noarbitrage conditions impose on policy — or have imposed them so tightly that policy was made impotent up front. In contrast, the microstructure approach allows some pro- 
fessional speculators to trade more successfully than others. Avoiding bang-bang (either zero or infinity) equilibrium profits, speculation imposes a significant restriction on policy, yet still leaves it with some room to maneuver. Hence the tension between the information-efficiency and risk-sharing role of prices, which forms the core of our analysis. Again, one may debate whether private information is the source the speculators' advantage in FX markets or just a simplifying assumption; we believe that the effects we have identified are generic and would survive in other settings.

Finally, the microstructure approach provides a setting where the structural aspects of various economies — whether emerging or well developed, having thin or liquid FX markets - can be modeled with great detail. Thus, modeling may specify the nature of market incompleteness, the extent to which speculators have an advantage over ordinary traders, or the competitiveness of the market; all these structural aspects are directly relevant to the policy question. Indeed, the microstructure model introduces the institutional dimension into analyses of exchange-rate policy. In that respect, the analogy between FX dealers and central banks from which we begun our investigation is not coincidental; rather, it is a reflection of similar constraints imposed by traders on institutions whose role is to provide liquidity to the market.

\section{Appendix}

\section{Proof of Proposition 4}

Since $\mu_{m}$ and $\mu_{q}$ are not affected by any of the external parameters mentioned in the proposition, the elasticity is determined by $\lambda_{F}$ alone.

We restate equation (15) as

$$
\lambda_{F}=\frac{\rho_{n} \widetilde{B}}{\sqrt{\widetilde{K}}-1 / S},
$$


where

$$
\begin{aligned}
\widehat{K} & =\frac{\rho_{n}^{2}\left(\sigma_{n}^{2} / S\right)(1-\theta l)^{2}}{l(1-l)}, \\
\widehat{B} & =(1-\theta l)^{2} \theta+(\theta l)^{2}(1-\theta), \\
S & =\sigma_{p}^{2}+\sigma_{\varepsilon}^{2}, \quad l=\frac{N}{N+1} .
\end{aligned}
$$

The first three partial derivatives are immediate.

To find the partial derivative with respect to $\theta$, compute

$$
\frac{\partial \lambda_{F}}{\partial \theta}=\rho_{n} \frac{\frac{\partial \widetilde{B}}{\partial \theta}\left(\sqrt{\widetilde{K}}-\frac{1}{S}\right)-\frac{\widehat{B}}{2 \sqrt{\widehat{K}}} \frac{\partial \widehat{K}}{\partial \theta}}{\left(\sqrt{\widetilde{K}}-\frac{1}{S}\right)^{2}} .
$$

Then

$$
\begin{gathered}
\frac{\partial \widehat{K}}{\partial \theta}=-2 \widehat{K} \frac{\theta}{(1-\theta l)}<0, \\
\frac{\partial \widehat{B}}{\partial \theta}=1+2 \theta l(l-2) .
\end{gathered}
$$

If $\theta<1 /[2 l(2-l)]$, then $\partial \widehat{B} / \partial \theta>0$ and $\partial \lambda_{F} / \partial \theta>0$. Simulations that we have conducted show that this sufficient condition is quite weak in the following sense: even when the condition is not satisfied, the direction of the comparative static remains unchanged for a large set of parameters.

\section{References}

[1] Alesina, Alberto and Laurence Summers (1993). "Central Bank Independence and Macroeconomic Performance: Some Comparative Evidence." Journal of Money, Credit and Banking, 25, 151-162.

[2] Calvo, Guillermo and Carmen Reinhart (2002). "Fear of Floating." Quarterly Journal of Economics, 117, pp. 379-408.

[3] Chen, Yu-chin (2002). "Exchange Rates and Monetary Policy: the Case for Commodity Economies." Working paper, Harvard University. 
[4] Cheung, Yin Wong and Clement Yuk Pang Wong (2000). "A Survey of Market Practitioners' Views on Exchange Rate Dynamics." Journal of International Economics, 51, pp. 401-419.

[5] DeLong, J. B., A. Shleifer, L. Summers and R. Waldmann (1990). "Noise Trader Risk in Financial Markets." Journal of Political Economy, 98, pp. 703-738.

[6] Devereux, Michael B. and Charles Engel (1998). "Fixed vs. Floating Exchange Rates: How Price Settings Affects the Optimal Choice of Exchange-Rate Regime." NBER Working Paper 6867.

[7] Djivre, Joseph and Daniel Tsiddon (2001). "A Monetary Labyrinth: Instruments and the Conduct of Monetary Policy in Israel 1987-1998." Working paper. The Research Department, Bank of Israel.

[8] Djivre, Joseph (1993). "The Exchange Rate Band in Israel and the Bank of Israel Daily Intervention in the Foreign Exchange Market" (in Hebrew). Working paper, Research Department, Bank of Israel.

[9] Dow, James and Rohit Rahi (2000). "Should Speculators Be Taxed?" Journal of Business, 73, pp. 89-107.

[10] Ellul, Andrew (2001). "The Dealers Ride Again: Volatility and Order Flow Dynamics in a Hybrid Market." Financial Markets Group, DP 368.

[11] Evans, Martin D. and Richard K. Lyons (2002). "Order Flows and Exchange Rate Dynamics." Journal of Political Economy, 110, pp. 170-180.

[12] Fischer, Stanley (2001). "Exchange Rate Regimes: Is the Bipolar View Correct?" Journal of Economic Perspectives, 15(2), pp. 3-24.

[13] Frankel, Jeffery G., Gordi Galli, and Alberto Giovannini (eds.) (1996). The Microstructure of the Foreign Exchange Markets. University of Chicago Press.

[14] Frankel, Jeffrey A., Sergio Schmukler, and Luis Serven (2001). "Verifiability and the Vanishing Exchange Rate Regime." In S. Collins and D. Rodrik (eds.), Policy Challenges in the Next Millennium, pp. 59-109. Washington, DC: Brookings Institution. 
[15] Friedman, Milton (1953). "The Case for Flexible Exchange Rates." In Essays in Positive Economics. University of Chicago Press.

[16] Helpman, Elhanan and Assaf Razin (1982). "A Comparison of Exchange Rate Regimes in the Presence of Imperfect Capital Markets." International Economic Review, 23, pp. 365-389.

[17] Hirshleifer, J. (1971). "The Private and Social Value of Information and the Reward to Inventive Activity." American Economic Review, 61(4), pp. 561-574.

[18] Ito, Takatoshi, Richard Lyons, and Michael T. Melvin (1998). "Is There Private Information in the FX Market? The Tokyo Experiment." Journal of Finance, 53, pp. $1111-1130$.

[19] Jeanne, Oliver and Andrew K. Rose (2002). "Noise Trading and Exchange Rate Regimes." Quarterly Journal of Economics, 117, pp. 537-569.

[20] Killeen, William, Richard Lyons and Michael M. Moore (2001). "Fixed versus Flexible: Lessons from EMS Order Flow." Working paper, UC Berkeley.

[21] Krugman, Paul (1979). "A Model of Balance-of-Payment Crises." Journal of Money, Credit and Banking, 11, pp. 311-325.

[22] Kyle, Albert (1985). "Continuous Auctions and Insider Trading." Econometrica, 53, pp. $1315-1335$.

[23] Lyons, Richard K. (1997). "A Simultaneous Trade Model of the Foreign Exchange Hot Potato." Journal of International Economics, 42, pp. 275-298.

[24] Lyons, Richard K. (2001). The Microstructure Approach to Exchange Rates. Cambridge: MIT Press.

[25] Marston, Richard (1985). "Stabilization Policies in Open Economies." In Ronald W. Jones and Peter B. Kenen (eds.) Handbook of International Economics, Amsterdam: Elsevier Science Pub.

[26] McKinnon, Ronald and Gunther Schnabl, (2003). "The East Asian Dollar Standard, Fear of Floating and Original Sin.” Working paper, Stanford University. 
[27] Morris, Stephen and Hyun Song Shin (1998). "Unique Equilibrium in a Model of Self-Fulfilling Currency Attacks." American Economic Review, 88(3), pp. 587-597.

[28] Naranjo, Andy and M. Nimalendran (2000). "Government Intervention and Adverse Selection Costs in Foreign Exchange Markets." Review of Financial Studies, 13, pp. 453-477.

[29] Neumeyer, Pablo Andres (1998). "Currencies and the Allocation of Risk: The Welfare Effects of Monetary Union." American Economic Review, 88(1), pp. 246259.

[30] Pagano, M. and A. Roell (1990). "Trading Systems in European Stock Exchanges: Current Performance and Policy Options.” Economic Policy, 10, pp. 65-115.

[31] Panayides, Marios (2004). "The Specialist's Participation in Quoted Prices and the NYSE's Price Continuity Rule." Working paper, Yale University.

[32] Shiller, Robert J. (1981). "Do Stock Prices Move too Much to Be Justified by Subsequent Changes in Dividends?" American Economic Review, 71(3), pp. 421-437.

[33] Spiegel, Matthew and Avanidhar Subrahmanyam (1992). "Informed Speculation and Hedging in a Noncompetitive Securities Market." Review of Financial Studies, 5, pp. $307-329$.

[34] Subrahmanyam, Avanidhar (1998). "Transaction Taxes and Financial Market Equilibrium." Journal of Business, 71, pp. 81-118.

[35] Tobin, James (1978). "A Proposal for International Monetary Reform." Eastern Economic Journal, 153, pp. 1-15.

[36] Taylor, Dean (1982). "Official Intervention in the Foreign Exchange Market." Journal of Political Economy, 90, pp. 356-368.

[37] Viswanathan, S. and J. Wang (2002). "Market Architecture: Limit Order Books Versus Dealership Markets." Journal of Financial Markets, 5, pp. 127-167.

[38] Vitale, Paolo (1999). "Sterilised Central Bank Intervention in the Foreign Exchange Market." Journal of International Economics, 49, pp. 245-267. 
[39] Vitale, Paolo (2003). "Foreign Exchange Intervention: How to Signal Policy Objectives and Stabilise the Economy." Journal of Monetary Economics, 50, pp. 841-870. 